\title{
HIGH THROUGHPUT ULTRA PERFORMANCE LIQUID CHROMATOGRAPHY - MASS SPECTROMETRIC METHOD FOR DETERMINATION OF ADRENALINE AND CHARACTERIZATION OF ITS STRESS DEGRADATION PRODUCTS: A MECHANISTIC APPROACH
}

\author{
MASOOM R. SIDDIQUI ${ }^{a, *}$, SAIKH M. WABAIDUR, ZEID A. ALOTHMAN ${ }^{a}$, M.Z.A. RAFIQUEE \\ MOONIS ALI KHAN", SADIA SUMBULC \\ a Advanced Materials research Chair, Department of chemistry, College of Science, King Saud University, Riyadh. Saudi Arabia. 11451 \\ ${ }^{b}$ Department of Applied Chemistry, Aligarh Muslim University, Aligarh, U.P. India \\ ${ }^{c}$ Department of Chemistry, College of Science, Princess Noura Bint Abdul Rehman University, Riyadh, Saudi Arabia
}

\begin{abstract}
UPLC-MS analytical procedure has been established for the determination of adrenaline in marketed formulation and in the pure form. The detection of the adrenaline was executed considering positive electrospray ionization (ESI) and selected ion reaction (SIR) modes. Chromatographic separation was achieved using ACQUITY UPLC BEH $\mathrm{C}_{18}$ column $(100 \mathrm{~mm} \times 2.1 \mathrm{~mm}, 1.7 \mu \mathrm{m}$ particles size $)$ using a binary mobile phase mixture of methanol and water (50:50). The mobile phase was set to flow at the rate of $0.3 \mathrm{ml} \mathrm{min}{ }^{-1}$. The run time time for adrenaline was as short as 1.5 minutes. Linearity was found to be over the concentration range of $1 \mu \mathrm{g} \mathrm{ml}^{-1}-6 \mu \mathrm{g} \mathrm{ml}^{-1}$. An excellent recovery of $100.18 \%-100.68 \%$ was achieved using this procedure. The standard deviation ranged from $0.014-$ 0.118 in intra-day studies and $0.016-0.096$ in case of inter-day studies. The procedure's quantitation limit was $0.76 \mu \mathrm{g} \mathrm{ml}{ }^{-1}$ and detection limit was $0.25 \mu \mathrm{g} \mathrm{ml}{ }^{-1}$. The method was successfully applied to determine adrenaline in drug formulations. In order to get the information about the stability of adrenaline in various environments forced degradation studies were conducted and the characterization of the stressed samples were performed using mass spectrometry.
\end{abstract}

Keywords: Adrenaline, UPLC-MS method, pharmaceutical analysis, forced degradation study

\section{INTRODUCTION}

Adrenaline, Chemically known as (R)-4-(1-hydroxy-2-(methylamino) ethyl) benzene-1,2-diol is a hormone and neurotransmitter which is widely applied for the management of heart failure. ${ }^{1}$ Another important application of adrenaline is heart rate increament, blood vessels constriction, air passage dilation. It is also known as epinephrine and participates in fight or flight response of the sympathetic nervous system. The year 1900 saw the discovery of the drug adrenaline by Uenaka. ${ }^{2}$

It is white to nearly white crystalline powder and administered as injection owing to its destruction in gastrointestinal tract and its oxidation in liver. Since adrenaline is a hormone and a neurotransmitter it acts on almost all the body tissues but the action varies from tissue to tissue depending upon the type and expression of adrenergic receptors. Adrenaline is listed in United States pharmacopeia ${ }^{3}$ and the official method of analysis in the official monograph is non-aqueous titration method with perchloric acid having crystal violet solution as indicator. Owing to its significance in human life many analytical methods have been developed to quantitate the adrenaline in its formulations and biological fluids. Spectrophotometry has been a choice by many of the researchers in the analysis of adrenaline. ${ }^{4-8}$ Since its initiation in second half of $\mathrm{XX}$ century, laboratory automation played an important role in the analysis of pharmaceuticals, in the analysis of adrenaline flow injection methods has been widely used. ${ }^{9-13}$ Among the determination technique high performance liquid chromatography (HPLC) remains an important instrument of high importance, adrenaline too has been quantitated by HPLC. ${ }^{14-15}$ Other techniques involved in the determination of adrenaline include fluorimetry ${ }^{16-18}$ and UPLC-MS/ MS. ${ }^{19-20}$ Few other researches have recently been reported for the determination and mechanistic studies of adrenaline as well. ${ }^{21-25}$ The characterization of the forced degradation products has previously has also been previously been done using mass spectrometry. ${ }^{26}$

The current study aims at developing a simple and fast method for the quantitative analysis of adrenaline in pharmaceutical formulation and characterization of possible degradation products that might be formed during the various steps, from synthesis to consumption.

\section{EXPERIMENTAL SECTION}

\subsection{Reagent and standard}

Adrenaline reference standard was purchased from Sigma Aldrich while methanol used in the chromatographic estimation of adrenaline was obtained from BDH prolabo. Forced degradation samples were prepared using the Merck produced Sodium hydroxide and $\mathrm{HCl}$ and $\mathrm{BDH}$ manufactured hydrogen peroxide.
2.2. Standard and quality control-Sample preparation

2.2.1. solution preparation-Standard

For UPLC-MS method, $12.5 \mathrm{mg}$ of adrenaline was taken in $50 \mathrm{ml}$ standard flask and dissolved in same volume of milli Q generated water thus preparing a $0.25 \mathrm{mg} \mathrm{ml}^{-1}$ stock solution further required solutions were prepared by diluting the prepared standard.

Preparation of the test solution from the pharmaceutical formulations

Five vials of adrenaline injection (manufactured by Antigen pharmaceuticals, Ireland) with $1 \mathrm{mg}$ per $\mathrm{ml}$ label claim was broken and mixed in $5 \mathrm{ml}$ milli Q water in a $10 \mathrm{ml}$ standard flask further $5 \mathrm{ml}$ of the content was dissolved in $10 \mathrm{ml}$ standard volumetric flask to get $0.25 \mathrm{mg} \mathrm{ml}^{-1}$ test solution.

Preparation of forced degradation products

The forced degradation studies of adrenaline were carried out individually under acidic, basic thermal and oxidation conditions. Acidic degradation was carried out by dissolving $1 \mathrm{ml}$ of the stock solution $\left(0.25 \mathrm{mg} \mathrm{ml}^{-1}\right)$ with $0.5 \mathrm{~N}$ $\mathrm{HCl}$ and heating the content at $60^{\circ} \mathrm{C}$ for 1 hour, then the samples were cooled and neutralized with $0.5 \mathrm{~N} \mathrm{NaOH}$ and diluted upto the mark in a $50 \mathrm{ml}$ standard volumetric flask. In the similar way the basic degradation was achieved by treating $1 \mathrm{ml}$ of the standard adrenaline in a $50 \mathrm{ml}$ standard flask and further treating it was $0.5 \mathrm{~N} \mathrm{NaOH}$ and heating for 1 hour at $60{ }^{\circ} \mathrm{C}$, the base degraded solution was further neutralized using $0.5 \mathrm{~N} \mathrm{HCl}$ and was made upto the mark. The oxidative stress degradation sample of adrenaline was prepared in a $50 \mathrm{ml}$ standard flask by dissolving $1 \mathrm{ml}$ of $0.25 \mathrm{mg} \mathrm{ml}^{-1}$ adrenaline in $1 \% \mathrm{H}_{2} \mathrm{O}_{2}$ and heating the content at $60{ }^{\circ} \mathrm{C}$ for 1 hour the content was cooled and made upto the mark. Thermal degradation of the adrenaline was carried out using the solid samples; in this case solid drug was heated at $40{ }^{\circ} \mathrm{C}$ for three days, further the $0.25 \mathrm{mg} \mathrm{ml}^{-1}$ was prepared and $1 \mathrm{ml}$ of the solution was dissolved in $50 \mathrm{ml}$ Milli $\mathrm{Q}$ water to obtain similar concentration. The Spectra of the forced degradation sample and the compound formed based on their $\mathrm{m} / \mathrm{z}$ ratio are mentioned in Figure 2-5.

2.3. Instruments and analytical conditions

The chromatographic analysis of adrenaline was carried out by Acquity waters UPLC system-mass detector. Acquisitions of data for quantification purposes were carried out using MassLynx ${ }^{\mathrm{TM}} 4.1$ software with QuanLynx ${ }^{\mathrm{TM}}$ program (Waters Corp., Milford, MA, USA). $\mathrm{C}_{18}$ column $(100 \mathrm{~mm} \times 2.1 \mathrm{~mm})$ and particle size of $1.7 \mu \mathrm{m}$ was applied for adrenaline quantification. All the experiments were carried out at $25^{\circ} \mathrm{C}$.

Chromatographic conditions

The chromatographic analysis of adrenaline was achieved on a ACQUITY UPLC BEH $\mathrm{C}_{18}$ column $(100 \mathrm{~mm} \times 2.1 \mathrm{~mm}, 1.7 \mu \mathrm{m}$ particle size $)$ using a binary mobile phase mixture of methanol and water $(50: 50, \mathrm{v} / \mathrm{v})$ at a flow rate of 0.3 $\mathrm{ml} \mathrm{min} \mathrm{m}^{-1} .5 \mu \mathrm{L}$ volume of standards and the drug formulation were injected for the quantitative analysis purpose. The injected standards or formulations 
of adrenaline were allowed to run for $1.5 \mathrm{~min}$ and the peak for the adrenaline appeared at 0.52 minutes.

Mass spectrometric conditions

A triple-quadrupole mass spectrometer (Micromass Quattro Premier) along with built-in ESI source was applied for adrenaline recognition. Primary vacuum to the mass spectrometer was provided by SOGEVAC SV40 BI modelled Oerlikon rotary pump. The mass spectrometer worked at positive ionization mode to generate $[\mathrm{M}+\mathrm{H}]^{+}$ion at $\mathrm{m} / \mathrm{z} 184$ (adrenaline). The monitoring conditions were optimized for adrenaline. The MS factors chosen for the analyses are capillary voltage $(3.0 \mathrm{kV})$; cone voltage $(15 \mathrm{v})$; source temperatures $\left(120^{\circ} \mathrm{C}\right)$ and desolvation temperature $\left(300{ }^{\circ} \mathrm{C}\right)$; the desolvation gas flow $\left(600 \mathrm{~L} \mathrm{~h}^{-1}\right)$ and cone gas flow $\left(60 \mathrm{~L} \mathrm{~h}^{-1}\right)$. High-purity nitrogen used during the MS operations was produced from its generator (Peak Scientific NM30LA)

\section{RESULT AND DISCUSSION}

\subsection{Optimization of chromatographic and MS conditions}

Adrenaline was estimated using UPLC-MS using a methanol: water mobile phase. During the optimization of the conditions various parameters were checked in order to get a good peak shape and considerable sensitivity. The concentration of the organic modifier has an important role to play in the ionization and determination of adrenaline. During the initial trials acetonitrile water combination was used to get the drug separated but the peak shape obtained were not good enough to report. However, replacing the acetonitrile with methanol resulted in relatively better peak shape. To optimize the concentration of methanol various ratio of methanol: water was tried and the best peak was obtained in 50:50 (methanol: water). The retention time (RT) of the adrenaline peak remained 0.53 minute, among the shortest RTs in the literature for adrenaline analyses.

Mass spectrometric exposure reveals the exact semblance of the studied material on the molecular mass ground.

In order to adjust the MS parameters for adrenaline analyses, $1 \mathrm{ppm}$ adrenaline solution was infused into the MS instrument and full scan was performed, the results indicated higher intensity at the positive ionization mode as compared to the negative ionization mode. The complete scan for the authentic sample of adrenaline was recorded is shown in Figure 1. The main peak having a mass/charge of 184 corresponds to that of adrenaline. The influence of capillary voltage $(2-4.5 \mathrm{kV})$, cone voltage $(10-100 \mathrm{~V})$, source temperature $\left(100-120{ }^{\circ} \mathrm{C}\right)$, and disolvation temperature $\left(200-400{ }^{\circ} \mathrm{C}\right)$ and disolvation gas flow $(500-700 \mathrm{~L} / \mathrm{h})$ was checked and it was observed that maximum intensity of adrenaline was obtained at the optimized parameters such as capillary voltage $3 \mathrm{kV}$, cone voltage $15 \mathrm{~V}$, source temperature $120^{\circ} \mathrm{C}$, and dissolvation temperature $300{ }^{\circ} \mathrm{C}$ and disolvation gas flow $600 \mathrm{~L} / \mathrm{h}$.
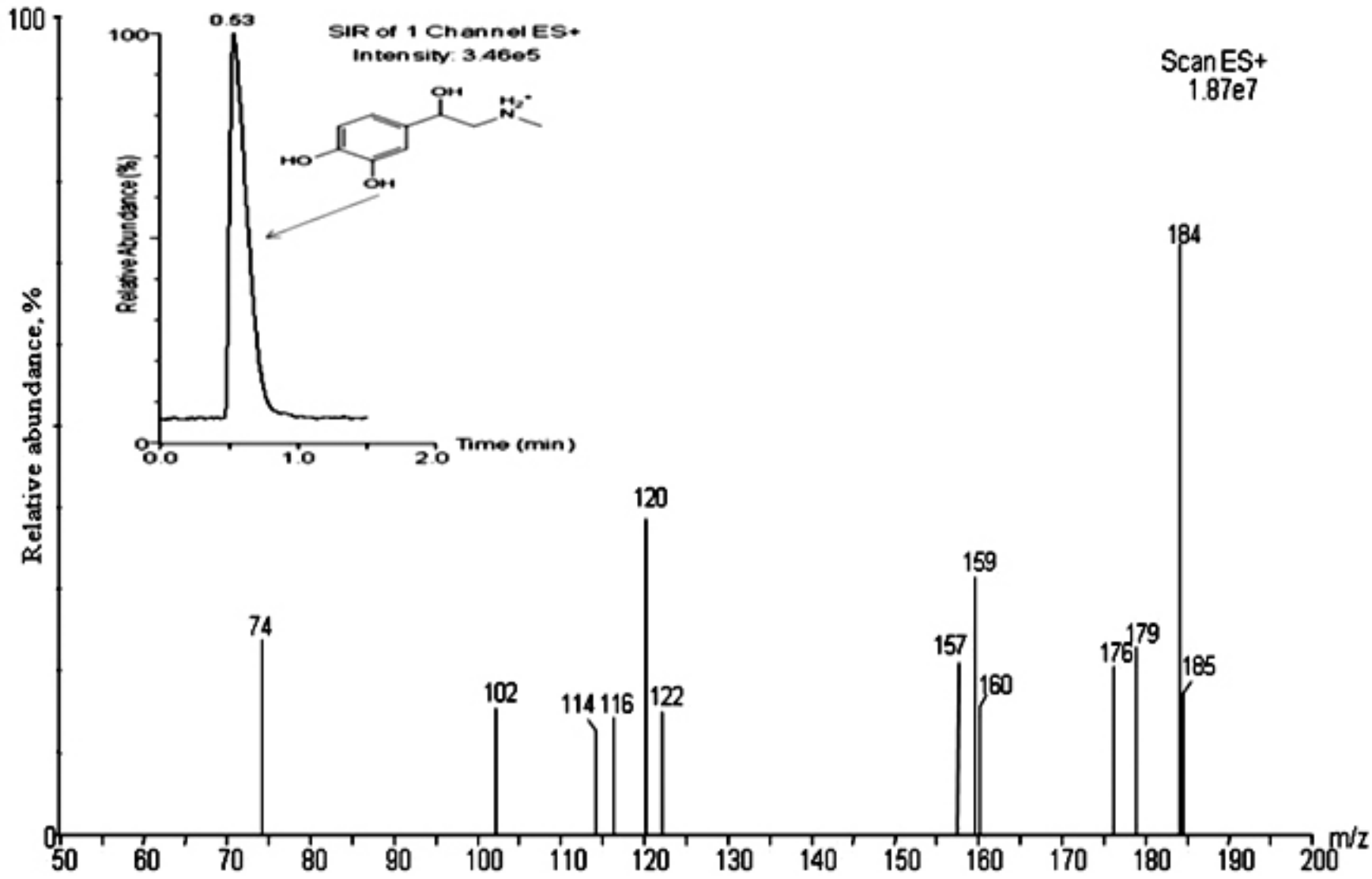

Figure 1: MS spectrum, and standard chromatogram (inset) of adrenaline using SIR mode.

\subsection{Method validation}

The method validation was accomplished as per the guidelines of International Conference on Harmonization (ICH). ${ }^{27}$ The factors investigated under the light of $\mathrm{ICH}$ recommendations are confirmation of identity, linearity, limit of detection and limit of quantitation, solution stability, accuracy and precision and specificity.

System suitability

ICH guidelines (Q2 R1) consider system suitability parameter as an important parameter for the analytical procedures. The system suitability test approves that the performance of the instrument; reagent and the columns remains suitable for the determination purpose. Briscoe et al ${ }^{28}$ in his article mentioned signal stability, response and carry over as key parameter to judge the system suitability. To ascertain the system suitability of the method, six different samples of adrenaline standard solution $\left(5 \mu \mathrm{g} \mathrm{ml}^{-1}\right)$ was introduced into the instrument and response in terms of the peak area was documented. The RSD (\%) of the peak area of six samples of adrenaline was $<2 \%$ indicating suitable system performance. The system was tested for the carryovers too, by injecting six blank solutions. The system qualifies its suitability test as no 
carryovers were recorded.

Linearity and calibration range

Linear response of the method was checked using seven different concentrations of standard adrenaline. Prior to the analysis of the linearity samples, blank solutions were analyzed to check the possible interference. Range of $1 \mu \mathrm{g} \mathrm{ml}^{-1}-6 \mu \mathrm{g} \mathrm{ml}^{-1}$ showed a linear response for adrenaline. After the regression treatment the correlation coefficient was found to be 0.9992 .

Accuracy and precision

Accuracy and precision are co-related term as accuracy has a little significance without precision. Where, accuracy is the difference between the observed value and the true value. The accuracy and precision studies were conducted as per the recommendations of the ICH guidelines. As per the guidelines, the accuracy and precision was evaluated at three levels of concentration i.e. $1.0,4.0$ and $6.0 \mu \mathrm{g} \mathrm{ml}^{-1}$. Inter day precision and intraday precision studies were performed in the quality controlled samples and results are mentioned in Table 1 which indicate that the relative standard deviation (RSD) values obtained are inside the tolerable limit with good recovery.

Limit of detection (LOD) and Limit of quantitation (LOQ)

Calculation of LOD and LOQ is a significant feature of analytical validation, the LOD and LOQ for adrenaline was calculated by means of signal-to-noise ratio which is 3:1 in case of LOD and 10:1 for LOQ. Six different blank samples the one spiked with the very low concentration of the analyte were injected to get detection and quantitation limits and were found to be $0.25 \mu \mathrm{g} \mathrm{ml}^{-1}$ and $0.76 \mu \mathrm{g} \mathrm{ml}^{-1}$.

\section{Application of the proposed procedure}

Determination of drug in pharmaceutical dosage form

The method was applied to determine adrenaline in drug formulation. The quantitative analysis of the adrenaline was performed in the antigen pharmaceuticals, Ireland manufactured ampoule having a label claim of $1 \mathrm{mg}$ $\mathrm{ml}^{-1}$ (Lot \# 12115041). The drug in the ampoule was found to be $0.9998 \mathrm{mg}$ corresponding to $99.98 \%$ which was in agreement with the claimed label.

Standard addition technique has been a choice of many analysts to make sure the validity of the developed method. The use of standard addition technique was also an effort to rectify the uncontrolled random errors instigated by other constituent in the method and also by the used appliance itself. During this investigation adrenaline in pure form $\left(1.0 \mu \mathrm{g} \mathrm{ml}^{-1}\right)$ was fortified to marketed product $\left(1.0,2.0\right.$ and $\left.5.0 \mu \mathrm{g} \mathrm{ml}^{-1}\right)$ and the nominal amount of adrenaline was evaluated. The results of the standard addition experiments are mentioned in

Table 1. Results obtained from this evaluation was quite satisfactory and no interference from the excipients in the formulation is observed

Table 1: Validation data summary of adrenaline determination by UPLC-MS

\begin{tabular}{|c|c|c|c|c|c|}
\hline \multicolumn{4}{|c|}{ Calibration Curve Range } & \multicolumn{2}{|c|}{$1 \mu \mathrm{g} \mathrm{ml}^{-1}-6 \mu \mathrm{g} \mathrm{ml}^{-1}$} \\
\hline \multicolumn{4}{|c|}{ Correlation coefficient $(n=5)$} & \multicolumn{2}{|c|}{0.992} \\
\hline \multicolumn{4}{|c|}{ LOD } & \multicolumn{2}{|c|}{$0.25 \mu \mathrm{g} \mathrm{ml}^{-1}$} \\
\hline \multicolumn{4}{|c|}{ LOQ } & \multicolumn{2}{|c|}{$0.76 \mu \mathrm{g} \mathrm{ml}^{-1}$} \\
\hline \multirow{2}{*}{ Accuracy \& Precision } & \multicolumn{3}{|c|}{ Amount $\left(\mu \mathrm{gml}^{-1}\right)$} & \multirow{2}{*}{$\begin{array}{l}\text { Standard } \\
\text { deviation }\end{array}$} & \multirow{2}{*}{ Relative Error } \\
\hline & Taken & & & & \\
\hline \multirow{3}{*}{ Intraday } & 1.0 & \multicolumn{2}{|c|}{1.002} & 0.014 & 0.002 \\
\hline & 4.0 & \multicolumn{2}{|c|}{3.987} & 0.064 & 0.003 \\
\hline & 6.0 & \multicolumn{2}{|c|}{6.01} & 0.118 & 0.002 \\
\hline \multirow{3}{*}{ Interday } & 1.0 & \multicolumn{2}{|c|}{0.999} & 0.016 & 0.001 \\
\hline & 4.0 & \multicolumn{2}{|c|}{4.003} & 0.075 & 0.001 \\
\hline & 6.0 & \multicolumn{2}{|c|}{6.04} & 0.096 & 0.007 \\
\hline \multicolumn{6}{|l|}{ Method Recovery } \\
\hline & \multicolumn{3}{|c|}{ Amount $\left(\mu \mathrm{gml}^{-1}\right)$} & \multirow{3}{*}{$\%$ Recovery } & \multirow{3}{*}{$100.18-100.68$} \\
\hline & Taken & Added & Found & & \\
\hline & 1.0 & 1.0 & 2.007 & & \\
\hline & 1.0 & 2.0 & 3.005 & $\%$ RSD & $2.04-2.66$ \\
\hline & 1.0 & 5.0 & 6.040 & & \\
\hline
\end{tabular}

Characterization of the forced degradation products 
<smiles>CN(C)CC(O)c1ccc(O)c(O)c1</smiles>

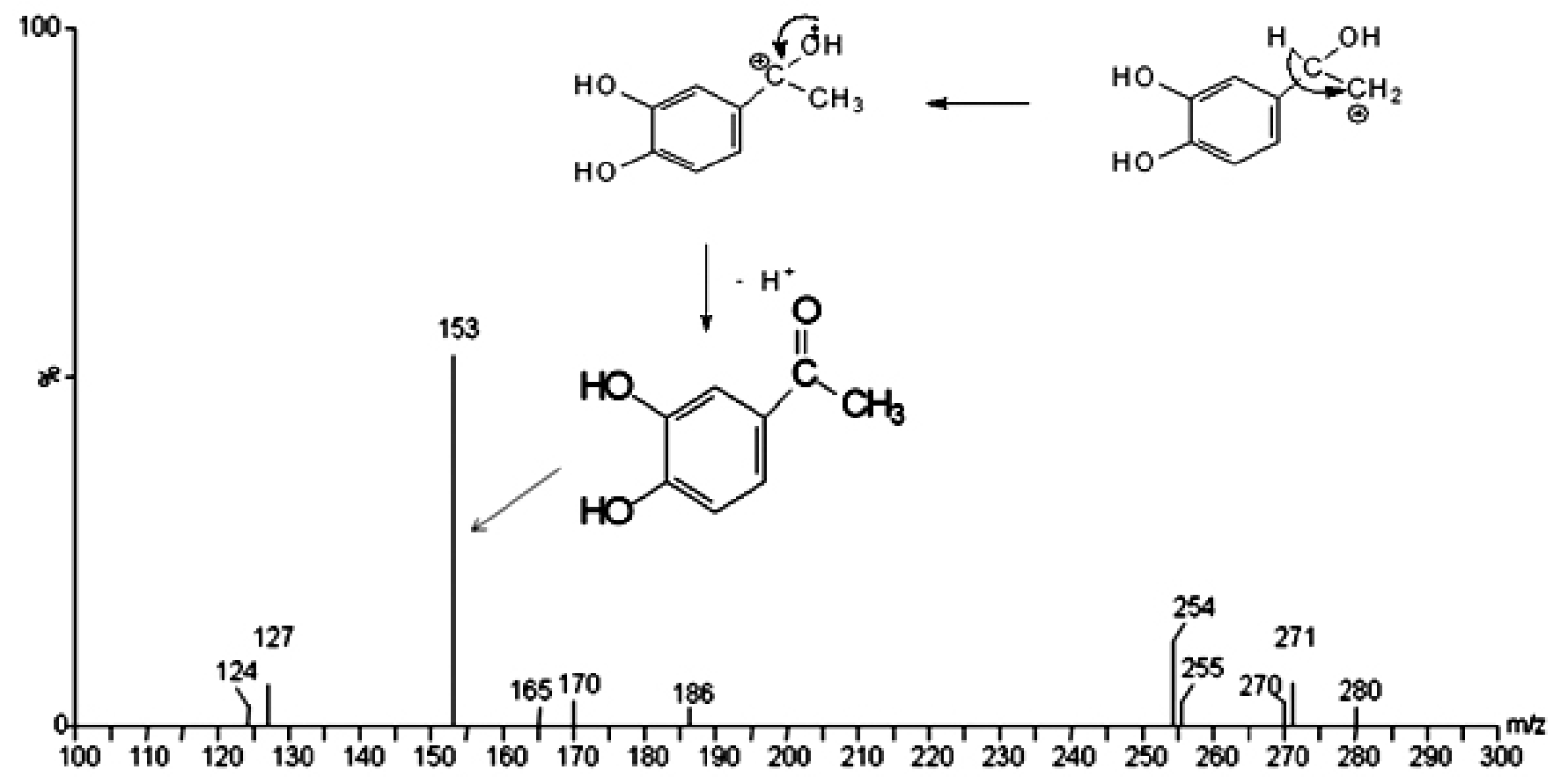

Figure 2: Spectra and mechanism showing the acid degradation of adrenaline

Thermal degradation of adrenaline

The strong heating of adrenaline results into the removal of water molecules to form alkene derivative this can be evident from the $m / z$ obtained i.e. 166. The same can be represented through the following mechanism the confirmation of the degradation product is shown in Figure 3

\section{Oxidative degradation}

The possible mechanism of oxidation of adrenaline by hydrogen peroxide is given below. The attack of hydrogen peroxide gives methyl amine and peroxide intermediate which on further degradation gives carbon dioxide, methanol and Catechol. The complete steps is shown in along with the supporting spectrum given in figure 4.

\section{Base degradation}

Adrenaline reacts with $\mathrm{NaOH}$ in the presence of dissolved oxygen and cyclizes to give adrenochrome. The adrenochrome exists in tautomeric forms 5 and 6 . The details of the mechanism and the formation of the degradation product were confirmed by MS spectra (figure 5). ${ }^{29}$

\section{Comparison of methods}

The proposed analytical methodology was compared with a few other analytical techniques previously reported for the determination of adrenaline in terms of quantitation limit, linear range, mobile phase, analysis time and recovery. In another method, a new ligand was synthesized for the determination of adrenaline ${ }^{4}$ and the method was provided an excellent linear range, but the synthesis of the ligand makes it a lengthy affair. For example, El-Kommos's ${ }^{8}$ developed a spectrophotometric method to determine the adrenaline using sodium periodate, while the method took an analysis time of 10 min with minimum use of the reagents. A very sensitive HPLC method was reported the detection limit of adrenaline $0.1097 \mathrm{ng} / \mathrm{ml}$, however the total run time was 10 minutes. ${ }^{14}$ Fluorimetric method for adrenaline was also reported in the literature and the method was linear in the range of $1.4 \times 10^{-9}-2.1 \times 10^{-6}$ $\mathrm{mol} / \mathrm{l}$, while the LOD was $2.4 \times 10^{-10} \mathrm{~mol} / 1 .{ }^{16}$ Other researcher was developed an UPLC MS/MS method and they reported a run time of 3.5 minutes for same purposes, but this method also requires a number of reagents, such as sodium metabisulfite, $\mathrm{HCl}$, anhydrous monobasic sodium phosphate, ammonium acetate, etc. for analysis purpose [20]. Spectrophotometric method using silver nanoparticle for determination of adrenaline was developed earlier and showed a comparable linearity of $1-12 \mu \mathrm{g} \mathrm{mL}^{-1}$ with a shorter analysis time and Lower LOD $\left(0.25 \mu \mathrm{g} \mathrm{ml}^{-1}\right)$, but it involves a number of reagents, such as CTAB, $\mathrm{NaOH}$ and $\mathrm{AgNO}_{3}{ }^{21}$ The current analytical method reported in this study is simple, fast as it take only 2 minutes of analysis time and it does not require any pretreatment procedures except the preparation of the forced degradation products. The detailed comparisons of the methods are mentioned in table 2 . 


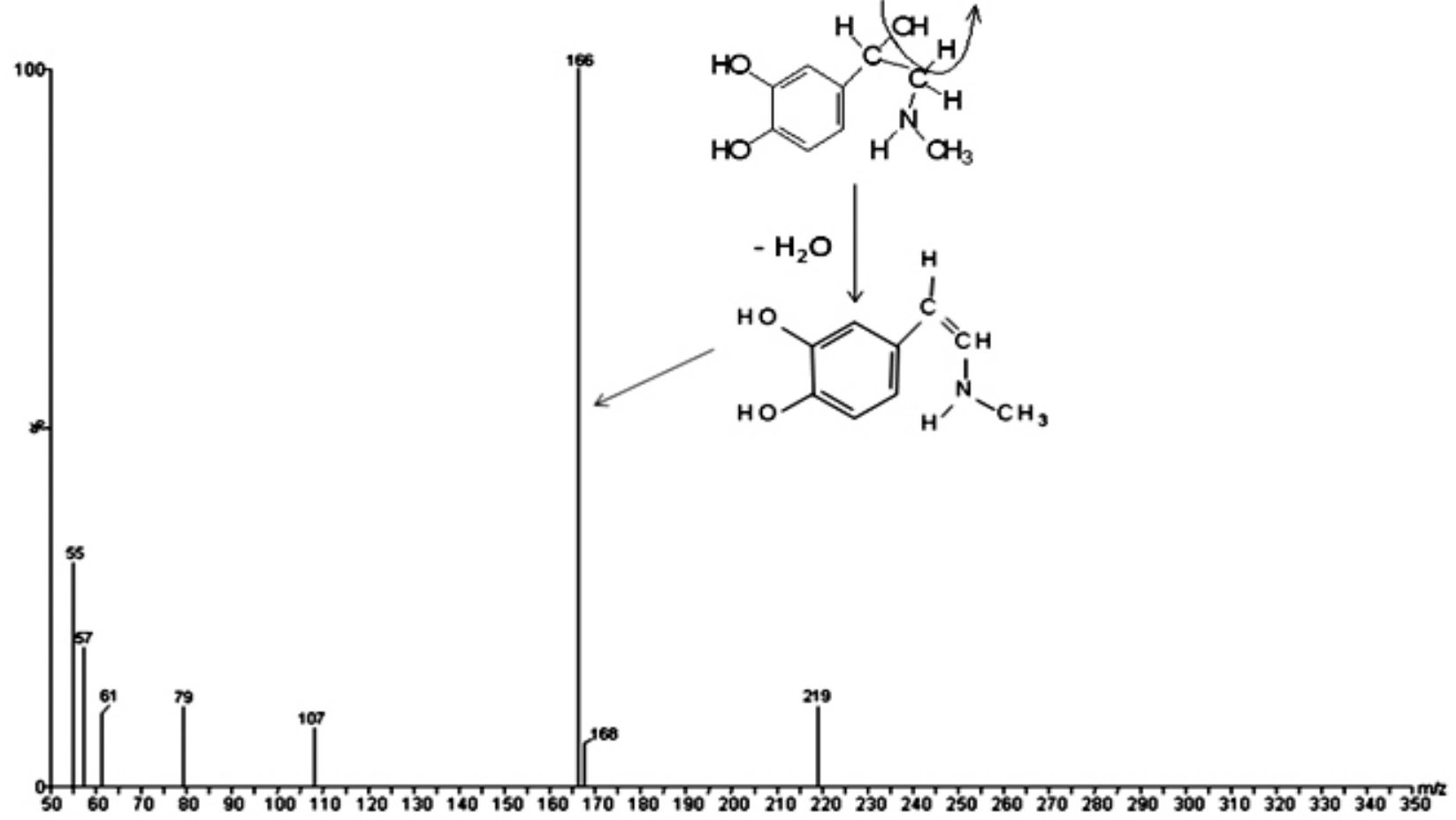

Figure 3: Spectra and mechanism showing the thermal degradation of adrenaline

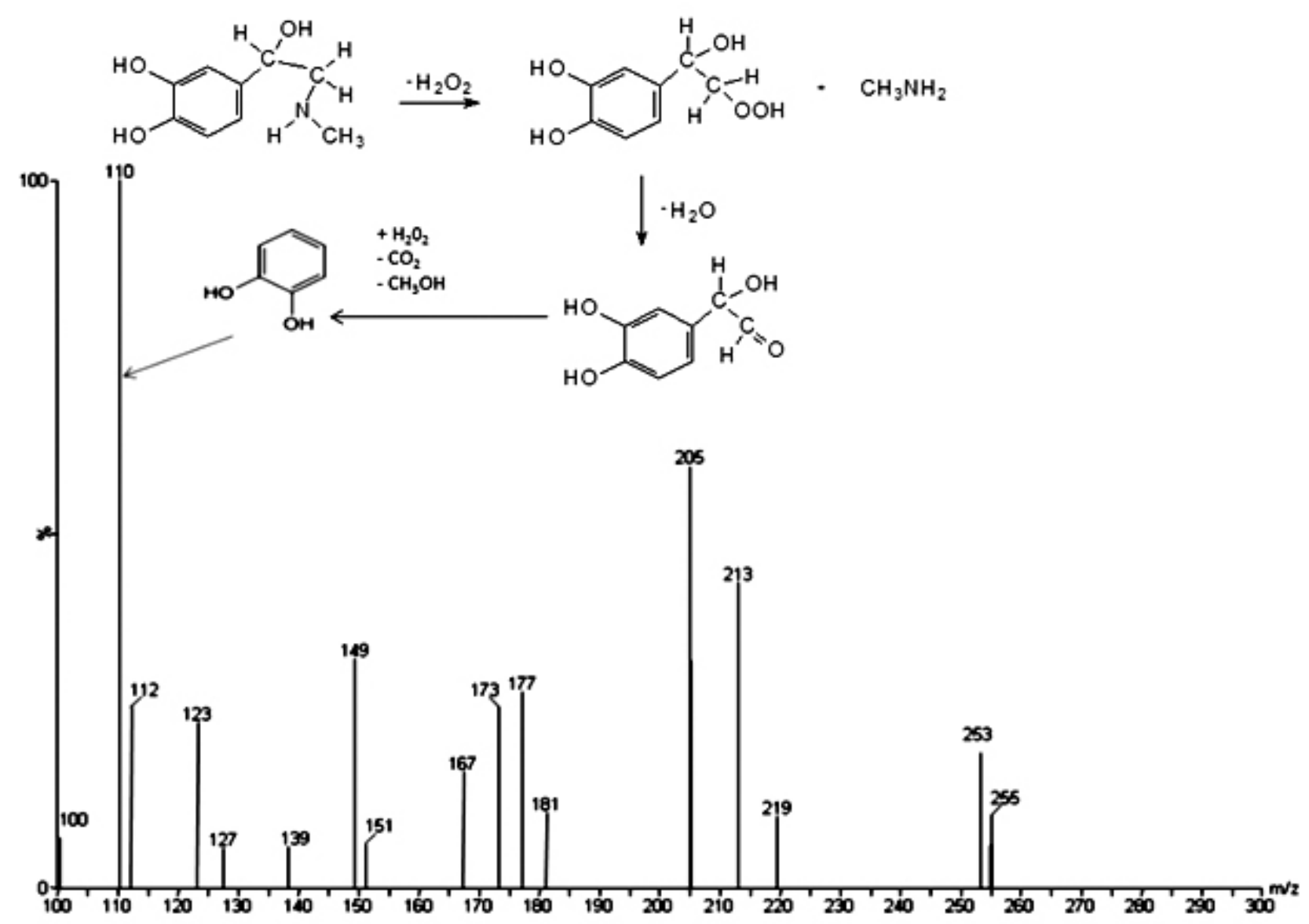

Figure 4: Spectra and mechanism showing the oxidative degradation of adrenaline 
<smiles>[R9]c1ccc(C(O)[CH]N([Y])C[C@H]([Y4])O)cc1O</smiles>

100

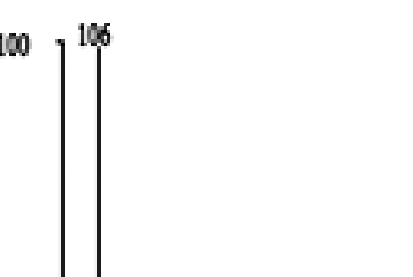<smiles>COC1=CC2C(=CC1=O)C(O)CN2C</smiles>

4

- $\mathrm{HO}_{2}$ fast $\frac{\mathrm{k}_{2}}{\text { fast }}$
5

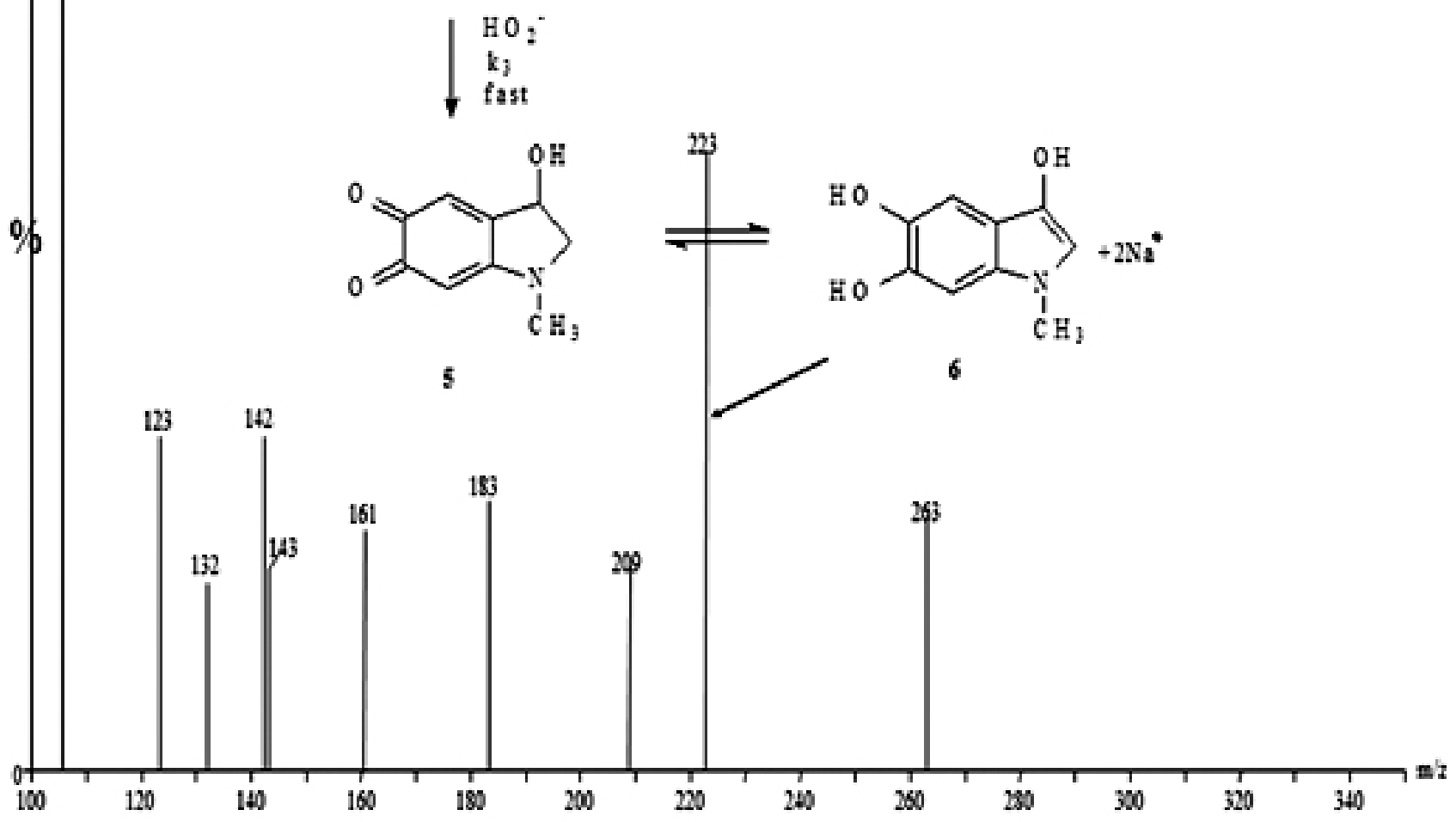
2<smiles>CN(C)CC(O)c1ccc(O)c(O)c1</smiles><smiles>C[14CH3]</smiles><smiles></smiles>

3
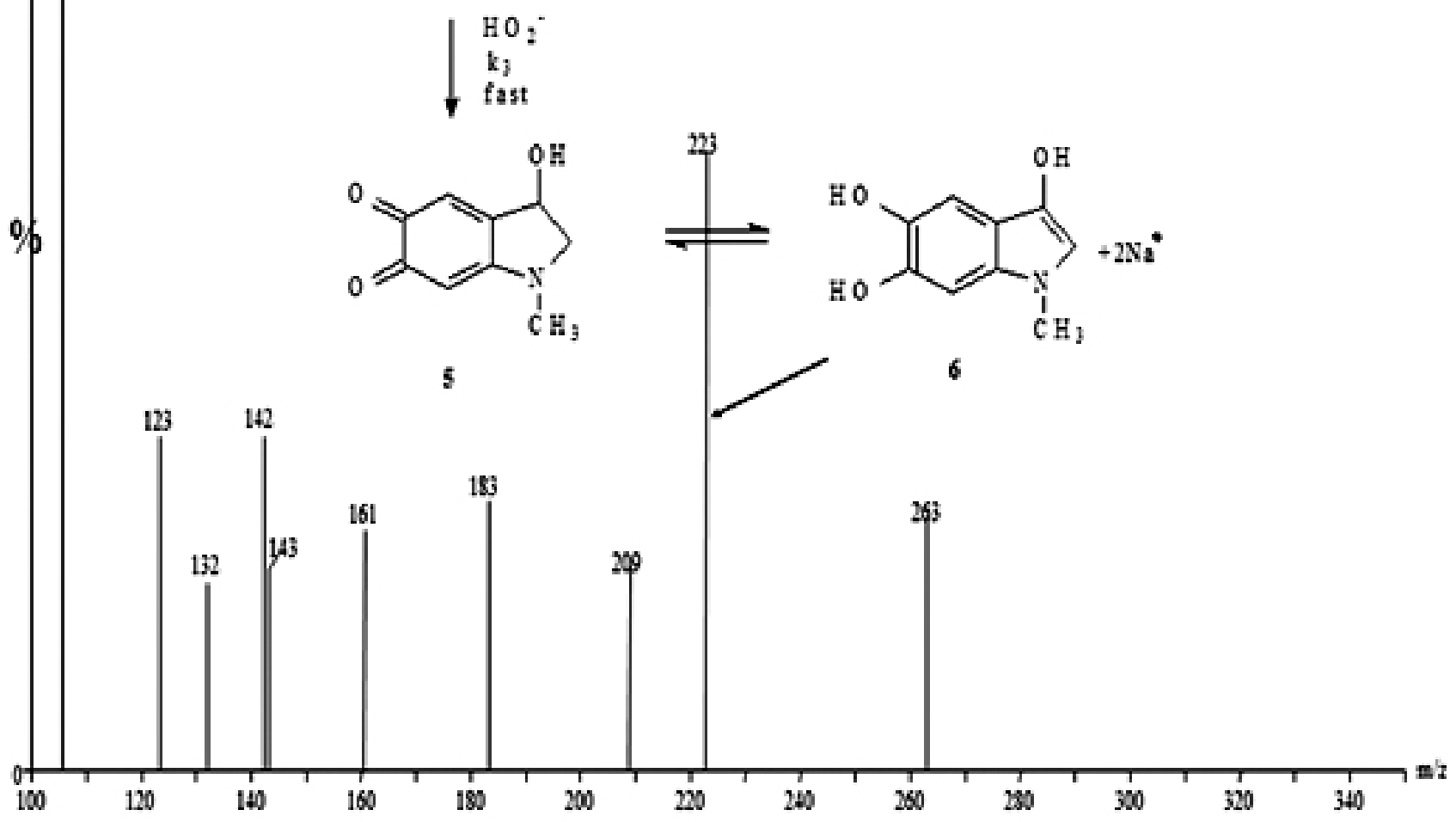

Figure 5: Spectra and mechanism showing the basic degradation of adrenaline 
Table 2: Comparision of the developed analytical procedure with existing methods.

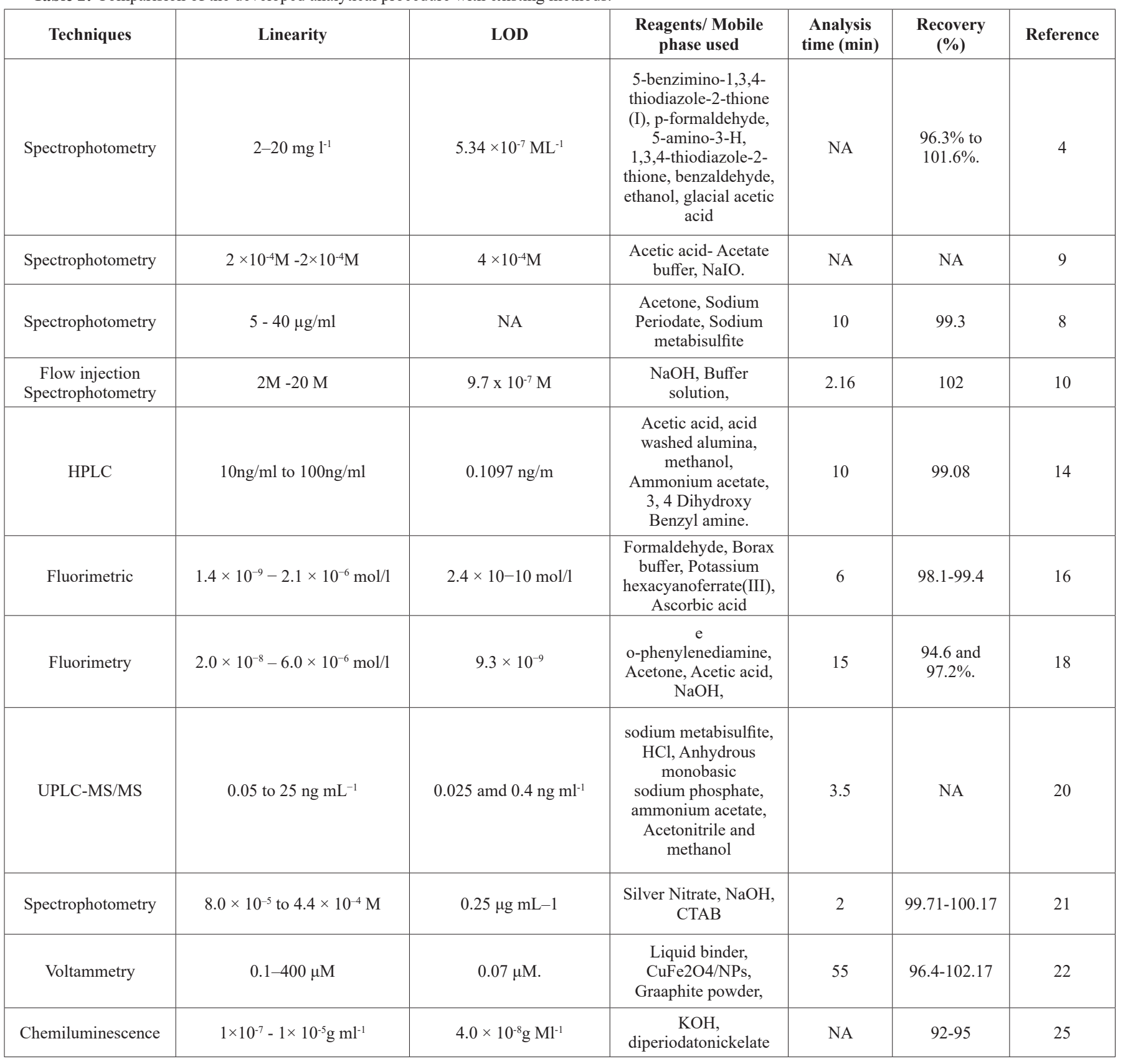

\section{CONCLUSION}

The developed procedure establishes a fast and accurate alternate to quantitate adrenaline. The current method utilizes takes only 1.5 minutes of analysis time which add to its advantage. To check the possible influence of the environmental factors such as acid, base, heat and oxidant forced degradation studies were conducted and the degradation products were identified by mass spectrometry based on their $\mathrm{m} / \mathrm{z}$ ratio. Thorough validation of the developed method was performed to ascertain that the method is serving its intended purpose. The developed method has excellent linearity and sensitivity which can be evident from the linear range $\left(1 \mu \mathrm{g} \mathrm{ml}^{-1}-6 \mu \mathrm{g} \mathrm{ml}^{-1}\right)$ and the LOD and LOQ which is $0.25 \mu \mathrm{g} \mathrm{ml}^{-1}$ and $0.76 \mu \mathrm{g} \mathrm{ml}^{-1}$, respectively. The analytical method was effectively applied to determine adrenaline in ampoule. Thus the proposed method is suitable for the determination of adrenaline in drug formulations and its routine analysis.

\section{ACKNOWLEDGEMENT}

The authors are grateful to the Deanship of Scientific Research, king Saud University for funding through Vice Deanship of Scientific Research Chairs.

\section{REFERENCES}

[1] K.H. Berecek, M.J. Brody. Am. J. Physiol. 242, H593,(1982).

[2] T. Yamashima. J. Takamine. J. med. Biog. 11, 95, (2003).

[3] Y. K. Kothari, K. Srinivasulu. Asian J Chem. 1, 42, (1989).

[4] S. A. H. Al-Ameri. Arab. J. Chem. (2011) Article in press.

[5] M. J. Hamzah, A. B. M. Mahood, S. A. Abid. J. karbala univ. 7, 9-14, (2009).

[6] M.R. H. Nezhad, J. Tashkhourian and J. Khodaveisi. J. Iran. Chem. Soc. 7, S83-S91, (2010). 
[7] S. R El-Shabouri, S. A. Hussein, A. A. Abdel-Alim. J. - Assoc. Off. Anal. Chemists - Canary Database.71, 764, (1988).

[8] M. E. Al-Kommos, F. A. Mohamed, A. S. Khedr. Talanta. 37, 625, (1990)

[9] J. J. Berzas Nevado, J. M. Lemus Gallego, P. Buitrago Laguna. Anal. Chim. Acta. 300, 293, (1995).

[10] J. J. Berzas Nevado, J. M. Lemus Gallego, P. Buitrago Laguna. J. Pharm. Biomed. Anal.14, 571, (1996).

[11] A. Ruiz Medina, M. L. Fernandez de Cordova, and A. Molina Diaz. Sensitive Mikrochem. Acta. 134, 101, (2000).

[12] L. K. Abdulrahman, A.M. Al-Abachi, M.H. Al-Qaissy. Anal. Chim. Acta. 538, 331. (2005).

[13] H. J. Vieira, O. Fatibello-Filho. Eclet. Quim. 29, 79, (2004).

[14] A. K. Mishra, A. Mishra, P. Chattopadhyay. Arch. Appl. Sci. Res., 2, 251, (2010).

[15] J. Westermann, W. Hubl, N. Kaiser, L. Salewski. Clin. lab. 48, 61, (2002).

[16] Y. Guo, J. yang, X. Wu, A. Du. J. Fluorescence. 15,131, (2005).

[17] Å. Bertler, A. Carlsson, E.Rosengren. Acta Physiol. Scand. 44, 273 , (1958).

[18] J. Yang, G. Zhang, X. Wu, F. Huang, C. Lin, X. Cao, L. Sun, Y. Ding. Anal. Chim. Acta. 363,105, (1988).
[19] B. J. Petteys, K. S. Graham, M.L. Parnás, C. Holt, E.L Frank. Clin. Chim. Acta. 413, 1459, (2012).

[20] C. Ji, J. Walton, Y. Su, M. Tella. Anal. Chim. Acta. 670, 84, (2010).

[21] M. R. Siddiqui, M. Z. Rafiquee, S. M. Wabaidur, Z. A. Alothman, M. S. Ali, H. A. Allohedan. Anal Sci. 31, 437 (2015).

[22] R. Bavandpour, H. Karimi-Maleh, M. Asif, V. K. Gupta, N. Atar, M. Abbasghorbani, J. Mol Liq. 213, 369 (2016).

[23] Z. Chen, Y. Hu, Q.Yang, C.Wan, Y.Tan, H. Ma. Sensors and Actuators B: 207, 277 ( 2015).

[24] M.Z.A. Rafiquee, M.R. Siddiqui, M. S. Ali, H. A. Al-Lohedan. Spectrochim Acta A.126, 21 (2014)..

[25] C. Yang, F.Chen, Z. Chang, Y. Sun, Z. Zhang. Spectrochim. Acta Part A $121,5,288$ (2014).

[26] M. R.Siddiqui, S.M. Wabaidur, Z. A. Alothman, H.Rahman, Md. Sarfaraz Alam, Md. Sajid Ali. J. Chil. Chem. Soc., Mar 2014, vol.59, no.1, p.23032307.

[27] ICH topic Q2 (R1) Validation of Analytical Procedures: Text and Methodology. C.J. Briscoe, M.R. Stiles, D.S. Hage, J. Pharm. Biomed. Anal., 44, 484, (2007).

[28] Abdullah S. Al-Ayed, Hamad A. Al-Lohedan, M.Z.A.Rafiquee, M. Sajid Ali, Zuheir A. Issa, Transition Met. Chem., 38, 173-181 (2013). 